\title{
Effects of acute heat stress on lipid metabolism of bovine primary adipocytes
}

\author{
M. P. Faylon, ${ }^{*}$ L. H. Baumgard, ${ }^{*}$ R. P. Rhoads, $†$ and D. M. Spurlock* ${ }^{* 1}$ \\ *Department of Animal Science, lowa State University, Ames 50011 \\ †Department of Animal and Poultry Sciences, Virginia Polytechnic Institute and State University, Blacksburg 24061
}

\begin{abstract}
Heat stress (HS) affects numerous physiological processes including nutrient partitioning and lipid metabolism. Objectives of this study were to evaluate how acute HS affects lipid metabolism in subcutaneous adipose tissue of dairy cattle. Adipose tissue biopsies were performed on Holstein cows for bovine primary adipocyte isolation and cultured at either $42^{\circ} \mathrm{C}(\mathrm{HS})$ or $37^{\circ} \mathrm{C}$ (thermal neutral, TN). Adipocytes were incubated with increasing isoproterenol (ISO), and with increasing concentrations of insulin in the presence of ISO to evaluate changes in lipolysis. Incorporation of radioactive acetate into lipids was measured as an indicator of lipogenesis. Abundance and phosphorylation of several lipolytic and lipogenic proteins were also measured. Adipocytes exposed to HS had an elevated maximal response to ISO and were more sensitive to lipolytic stimulation by ISO compared with cells cultured at TN. Thermal treatment did not affect the antilipolytic effects of insulin in the presence of ISO. Lipogenesis measured as acetate incorporation was not altered by HS, but a temperature by insulin interaction was observed for the regulation of acetyl CoA carboxylase, such that the presence of insulin resulted in a reduction in phosphorylation of acetyl CoA carboxylase in adipocytes cultured at TN but not HS conditions. Results of this study demonstrate that acute HS has a direct effect on the regulation of lipolysis and the rate-limiting enzyme of lipogenesis in isolated bovine adipocytes.
\end{abstract}

Key words: lipolysis, lipogenesis, beta-adrenergic receptor

\section{INTRODUCTION}

Heat stress (HS) is a physiological condition that occurs when the core body temperature of an animal exceeds a safe upper limit. Periods of HS result from a

Received April 9, 2015.

Accepted August 1, 2015.

${ }^{1}$ Corresponding author: moodyd@iastate.edu total heat load that is more than the animals' capacity for heat dissipation, thus prompting physiological and behavioral responses to reduce the strain (Bernabucci et al., 2010). In the United States alone, HS costs the dairy industry an estimated $\$ 1$ billion annually (StPierre et al., 2003).

In the past decade, alterations in the endocrine and metabolic status under hot environments have been reported in dairy cattle (Ronchi et al., 2001; Bernabucci et al., 2002, 2006; Rhoads et al., 2009). Ronchi et al. (1999) demonstrated that HS has a direct effect on lipid metabolism and liver enzymatic activities of Holstein heifers. In addition, changes in the oxidative status and circulating adipocytokine levels were observed in periparturient cows exposed to hot environments (Bernabucci et al., 2006). Furthermore, reduced feed intake only partially explains the decrease in milk yield during HS (Rhoads et al., 2009). In a series of pair-feeding experiments, plasma NEFA concentration in lactating dairy cows exposed to HS failed to increase, suggesting that these animals did not mobilize as much adipose tissue as their pair-fed, thermal neutral (TN) counterparts despite decreased DMI and loss of BW. Also, plasma insulin concentrations gradually increased in lactating cows and growing steers exposed to HS relative to pair-fed TN counterparts. Additionally, it has been demonstrated that heat-stressed cows have an increased insulin response to a glucose tolerance test (O'Brien et al., 2010; Wheelock et al., 2010), which may be essential in their adaptation mechanism to HS. Therefore, it is not clear if the blunted adipose tissue mobilization during HS is a direct result of hyperthermia on the adipocyte or indirectly due to heat-induced insulinemia.

In recent years, adipose tissue has received much attention due to the discovery of its role as a complex and highly active metabolic and endocrine organ (Kershaw and Flier, 2004). An accurate understanding of the biological mechanism(s) by which thermal stress affects adipose tissue metabolism and its effect on milk synthesis is critical for developing novel approaches (i.e., genetic, managerial, nutritional, or a combination of these) to optimize dairy cow performance, particularly during the summer months. Therefore, the objective 
of this study was to evaluate the direct effect of HS on lipid metabolism in the lactating dairy cow, particularly on the molecular regulators of lipolysis and lipogenesis in cultured bovine adipocytes. In this study, we investigated adipocyte sensitivity to lipolytic and antilipolytic signals to assess if HS (1) alters their lipolytic response to $\beta$-adrenergic receptor (BAR) agonists, and (2) enhances inhibition of lipolysis by insulin. We also investigated changes in the rate of incorporation of radioactive acetate in bovine cells to determine if HS enhances insulin-stimulated lipogenesis.

\section{MATERIALS AND METHODS}

\section{Animals and Adipose Tissue Biopsy}

The maintenance of the animals and the experimental procedures performed on them were carried out in accordance with the Iowa State University Animal Care and Use Committee guidelines and regulations.

Experiments were conducted during the spring months (late February until April) of 2012-2014 when cows were not exposed to environmental HS. Second to third lactation Holstein cows (230 to 400 d postpartum) with a BCS $>3.75$ were randomly selected for the studies to facilitate biopsy of an adequate quantity of adipose tissue. Subcutaneous adipose tissue biopsies (approximately $40 \mathrm{~g}$ ) were taken from between the pin and tail bone (ischial tuber and coccyx, respectively) of each cow using a minimally invasive procedure under local anesthesia (Faylon et al., 2014). Adipose tissue was placed in buffered saline solution with glucose, kept at $37^{\circ} \mathrm{C}$, and transported to the laboratory.

\section{Isolation of Adipocytes}

Primary adipocytes were harvested from adipose tissue biopsies. Samples were subjected to 2 rounds of 40-min collagenase digestion at $37^{\circ} \mathrm{C}$ in a water bath with shaking (100 cycles/min). Adipocytes were isolated using nylon filter mesh and washed with warmed cocktail buffer [Krebs-Ringer solution (20 mM sodium bicarbonate, $20 \mathrm{~m} M$ HEPES, $20 \mathrm{~m} M$ D-glucose), $1 M$ sodium bicarbonate, $1 M$ HEPES, $1 M$ glucose, $6 \%$ BSA, $1 \mathrm{mg} / \mathrm{mL}$ collagenase type 1a from Clostridium histolyticum (Sigma Aldrich)]. After removal of the infranatant, adipocytes were suspended in warmed explant medium $(1,000 \mathrm{mg} / \mathrm{L}$ of low glucose Dulbecco's modified Eagle medium, $4.4 \mathrm{~m} M$ sodium bicarbonate, $5 \mathrm{~m} M$ HEPES, $3 \%$ BSA), and approximately $900 \mu \mathrm{L}$ of this cell suspension was aliquoted into $20-\mathrm{mL}$ scintillation vials.

\section{Experimental Treatments}

Lipolysis Experiments. The cell suspensions were exposed initially and at 2-h intervals to a mixture of $95 \%$ air and $5 \% \mathrm{CO}_{2}$ and incubated in a gyratory incubator at $37^{\circ} \mathrm{C}$. Following a $1-\mathrm{h}$ acclimation period, cells were incubated under 2 experimental conditions for 1 h: $42^{\circ} \mathrm{C}$ (acute $\mathrm{HS}$ ) and $37^{\circ} \mathrm{C}(\mathrm{TN})$. Core body temperature of lactating dairy cows is approximately $38^{\circ} \mathrm{C}$. A slightly lower temperature was used to represent TN conditions because adipocytes were isolated from the subcutaneous adipose depot, which is expected to be maintained at a temperature slightly less than the core body temperature. Culturing cells at $42^{\circ} \mathrm{C}$ was done to represent a severe HS event in lactating cattle. This temperature was not reduced, as was done for the TN treatment, because extreme in vivo environmental conditions could exceed this temperature, potentially maintaining the elevated temperature in subcutaneous adipose depots during extreme HS. Subsequently, isoproterenol $\left(\right.$ ISO; $1.0 \times 10^{-5.5} M$ to $\left.1.0 \times 10^{-9} M\right)$ was added to the culture medium and cells were incubated for 90 min under HS or TN conditions. Each ISO dose was evaluated in 3 vials of cells for each thermal treatment, and this experimental protocol was replicated using adipocytes from 5 different cows. The incubation medium was aspirated after a 90-min incubation with ISO and stored at $-20^{\circ} \mathrm{C}$ until analysis. Approximately $400 \mu \mathrm{L}$ of protein homogenization buffer [10\% SDS, 1 $M$ sodium fluoride, $0.5 M$ EDTA, $1 M$ HEPES, $1 \mu \mathrm{L} /$ $\mathrm{mL}$ protease inhibitor (Sigma), $1 \mu \mathrm{L} / \mathrm{mL}$ phosphatase inhibitor (Sigma)] was added to the remaining cells and kept at $-80^{\circ} \mathrm{C}$ for subsequent protein extraction.

The lipolytic response of isolated primary adipocytes was also evaluated in the presence of insulin. As with the previous experiment, cells were exposed to the 2 temperature treatments $\left(37^{\circ} \mathrm{C}\right.$ and $42^{\circ} \mathrm{C}$ for $\mathrm{TN}$ and $\mathrm{HS}$ condition, respectively) following an hour-long acclimation period at $37^{\circ} \mathrm{C}$. Insulin (0 to $2.5 \mathrm{mU}$ ) was administered 30 min after exposure to the thermal treatments. After 30 -min incubation with insulin, ISO $\left(4.5 \times 10^{-7}\right.$ $M)$ was added into the cell suspension, and the adipocytes were incubated for $90 \mathrm{~min}$ before cell harvest. This concentration of ISO is that required to achieve half of the maximal lipolytic response, as determined for cells cultured under TN conditions in the previous experiment. The incubation medium was carefully removed and kept at $-20^{\circ} \mathrm{C}$ until further analysis. Protein homogenization buffer was added to the remaining cells and kept at $-80^{\circ} \mathrm{C}$ until protein extraction. Each insulin-temperature treatment combination was evaluated in triplicate vials of cells, and this experiment was repeated independently across 5 different cows. 
Lipogenesis Experiment. Adipocyte cell suspensions were exposed to a mixture of $95 \%$ air and $5 \% \mathrm{CO}_{2}$ before incubation, and every $2 \mathrm{~h}$ thereafter throughout the experimental period. The amount of acetate incorporation was measured to assess lipogenic activity of bovine adipocytes in response to insulin. Cells were acclimated at $37^{\circ} \mathrm{C}$ for $1 \mathrm{~h}$, after which they were exposed to the thermal treatments $\left(37^{\circ} \mathrm{C}\right.$ for $\mathrm{TN}$ and $42^{\circ} \mathrm{C}$ for HS) and allowed to acclimate for another $\mathrm{h}$. A final concentration of $1 \mu \mathrm{Ci}$ of $\left[1-{ }^{14} \mathrm{C}\right]$-acetate was added together with increasing concentrations of insulin $(0,0.5$, and $1 \mathrm{mU}$ ) to the cells. After a 3-h incubation period, reactions were terminated by the addition of $100 \mu \mathrm{L}$ of $17 \%$ perchloric acid to each vial. Each insulin dose per temperature treatment was evaluated in 3 vials of cells extracted from 8 cows.

Lipids were extracted from cells after carefully aspirating acidified media from the bottom of the vial, followed by the addition of Folch's reagent (chloroform/ methanol, 2:1, vol/vol). The cell-reagent mixture was agitated by placing the vials on top of a platform mixer for $15 \mathrm{~min}$, after which the crude extract was washed twice with $1 \mathrm{~N} \mathrm{NaCl}$. The solution was centrifuged at $805 \times g$ for $20 \mathrm{~min}$ at $4^{\circ} \mathrm{C}$, and the lower, lipid-containing chloroform phase was transferred to a new glass scintillation vial and allowed to evaporate to dryness overnight. Subsequently, $5 \mathrm{~mL}$ of scintillation cocktail (Sigma) was added to resuspend the lipids before quantification using a liquid scintillation counter.

\section{Glycerol Assay}

Glycerol content in the incubation medium served as an indicator of lipolysis and was determined by use of a colorimetric assay with free glycerol reagent following manufacturer's protocol (Sigma Aldrich, St. Louis, MO). Samples were run in triplicates in a 96-well format, and absorbance values were obtained using a Tecan Spectrafluor Plus (Tecan Group Ltd.). Glycerol concentrations were normalized to total protein extracted from cells cultured in each vial. The average of triplicate glycerol concentration values representing each of 3 replicate vials of cells per treatment combination was used in statistical analyses.

\section{Protein Extraction and Semiquantitative Western Blotting}

The protocol for the extraction and preparation of proteins for use in Western blotting has been previously described (Elkins and Spurlock, 2009). Bicinchoninic assay (Pierce Protein Research, Rockford, IL) was performed to determine protein concentrations, which were used to standardize the quantity of total protein loaded onto each gel. Semiquantitative Western blotting was performed to determine abundance of targeted proteins. Following transfer, membranes were blocked with $5 \%$ milk in TBS-T for at least $1 \mathrm{~h}$. Blots were incubated with specific primary antibodies at $4^{\circ} \mathrm{C}$ followed by incubation with anti-rabbit IgG horseradish peroxidase-linked secondary antibody from GE Healthcare (Pittsburgh, PA). Details about primary antibodies used have been published previously (Faylon et al., 2014). Proteins were detected with the ECL Plus Western Detection Kit (Amersham, Pittsburgh, PA) using an Alpha Innotech Imager (FluorChem FC2, Cell Biosciences, Santa Clara, CA) and quantified using Totallab software for 1D gel analysis (TL100, v2009, Totallab Ltd., Newcastle, Tyne, UK). All proteins were evaluated on duplicate gels, and average values across the gels were used in statistical analyses. A single arbitrarily chosen sample was included on each gel for normalization across gels.

\section{Calculations and Statistical Analysis}

The lipolytic response to ISO of isolated bovine adipocytes was evaluated by comparing the dose response curve of adipocytes cultured under HS versus TN conditions. A glycerol dose response curve was generated for cells representing each cow using the GraphPad Prism 5.00 software (GraphPad Prism for Windows, 2007). A Student's $t$-test was used to evaluate the effect of thermal treatment on several parameters including half maximal effective concentration $\left(\mathbf{E C}_{50}\right)$, slope, maximal response $\left(\mathbf{R}_{\max }\right)$ and baseline response. Main effects of thermal treatment, insulin concentration, and their interaction were evaluated.

Differences in abundance of lipolytic proteins according to thermal treatment and ISO concentrations were evaluated using mixed model equations. Thermal treatment and ISO concentration were evaluated as fixed factors, and cow as a random variable. The interaction of thermal treatment with ISO concentration was evaluated initially. This effect was nonsignificant $(P>0.05)$ for all proteins and was excluded from final analyses. When the overall effect of thermal treatment or ISO concentration was significant $(P<0.05)$, mean separations were determined using the P-DIFF procedure of SAS (SAS Institute Inc., 1999). Phosphorylated perilipin was often undetectable at lower concentrations of ISO. Therefore, phosphorylated perilipin was compared across ISO concentrations using a chi-squared test to determine if its presence or absence differed between thermal treatments.

For the lipogenesis study, acetate incorporation was analyzed using main effects of thermal treatment, insulin, and their interaction. All analyses were performed 
using SAS statistical software (SAS Institute Inc., 1999). All values are presented as means \pm SE, with the statistical significance set at $P<0.05$.

\section{RESULTS}

\section{Effects of HS on ISO Response}

The effect of HS on the lipolytic response of bovine adipocytes to ISO was evaluated by determining the glycerol dose response curve for each cow (Figure 1). Adipocytes cultured under HS had an elevated response to ISO, as indicated by increased $R_{\max }$ values in HS versus TN cells $(40.35 \mathrm{~m} M$ glycerol $/ \mathrm{mg}$ of protein versus $19.52 \mathrm{~m} M$ glycerol $/ \mathrm{mg}$ of protein, $P=0.02$ ). Additionally, HS cells were more sensitive to lipolytic stimulation by $\mathrm{ISO}$, depicted by lower $\mathrm{EC}_{50}$ values relative to cells cultured at TN conditions $\left(1.19 \times 10^{-7}\right.$ $M$ versus $\left.4.51 \times 10^{-7} M, P=0.04\right)$. However, neither basal lipolysis (glycerol release with no added ISO) nor the slope of the dose response curve differed between cells exposed to HS or TN environments $(P>0.05)$. A dramatic decrease in glycerol release was observed for HS cells at an ISO concentration of $1 \times 10^{-5.5} \mathrm{M}$ relative to lower ISO concentrations. However, this was not detected among cells incubated at TN temperature (Figure 1). This decline in glycerol concentration with HS treatment was consistent across cells from all 5 cows investigated.

\section{Effects of HS on Stimulated Lipolysis in the Presence of Insulin}

Consistent with the previous experiment, the overall lipolytic response to ISO was higher among HS-treated cells compared with cells maintained at TN $(P<$ 0.001; Figure 2). A significant interaction between insulin concentration and temperature was not observed $(P=0.83)$, but the glycerol release into the medium decreased with increasing insulin concentration $(P=$ 0.02). The basal (-ISO/-insulin) lipolytic response was not different between HS and TN cells $(P>0.05)$.

\section{Changes in Lipolytic Proteins in Response to HS}

Phosphorylation of hormone-sensitive lipase (HSL) at serine 563 (PHSL $\left._{\mathrm{Ser} 563}\right)$ differed $(P<0.001)$ between HS and TN cultured cells incubated with an ISO concentration of $1 \times 10^{-6} M$ (Figure 3$)$. Differences in total HSL levels in response to thermal stress and across different ISO concentrations were not observed $(P>$ 0.05). Thermal stress did not elicit a difference in total perilipin protein abundance (Figure 4B). Phosphorylation of perilipin was not always detected, particularly

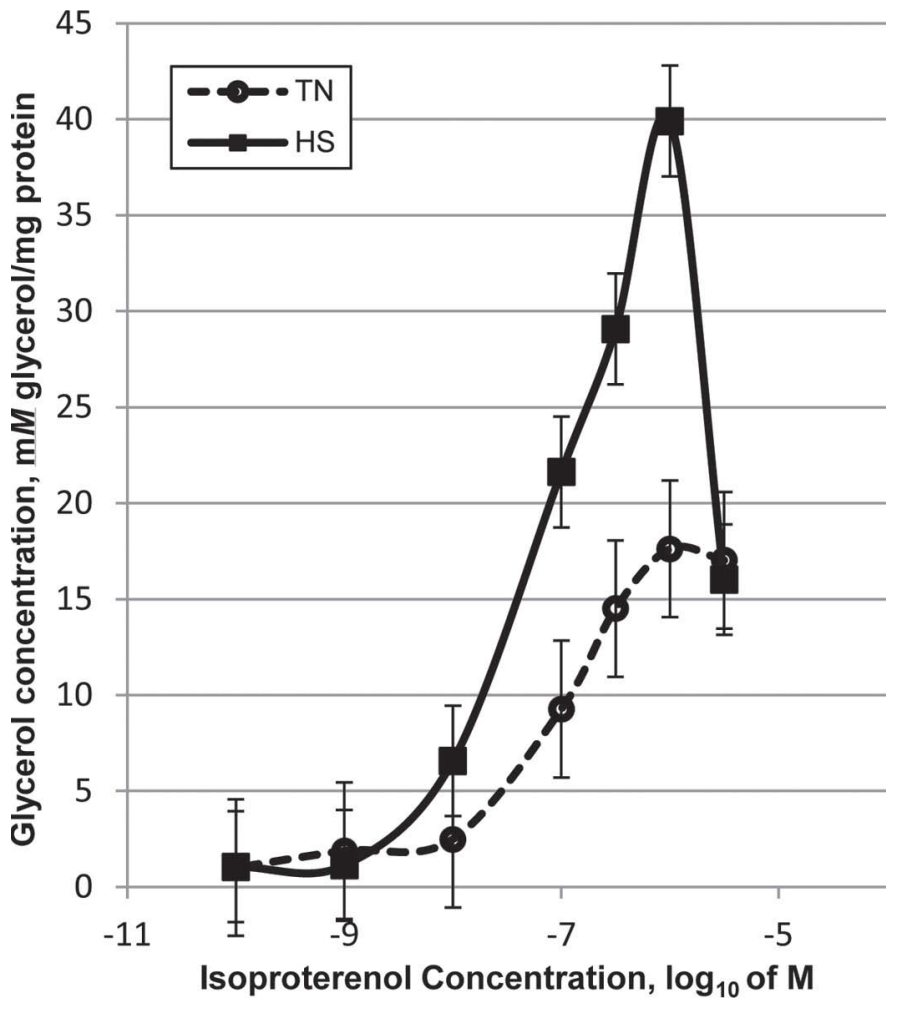

Figure 1. Effect of heat stress (HS) on the lipolytic response. Medium glycerol concentration was measured as an indicator of the lipolytic response of bovine primary adipocytes to isoproterenol. Data represent the average glycerol concentration across cells isolated from 5 cows for each isoproterenol by temperature (HS or thermal neutral, $\mathrm{TN}$ ) treatment combination, and SE bars.

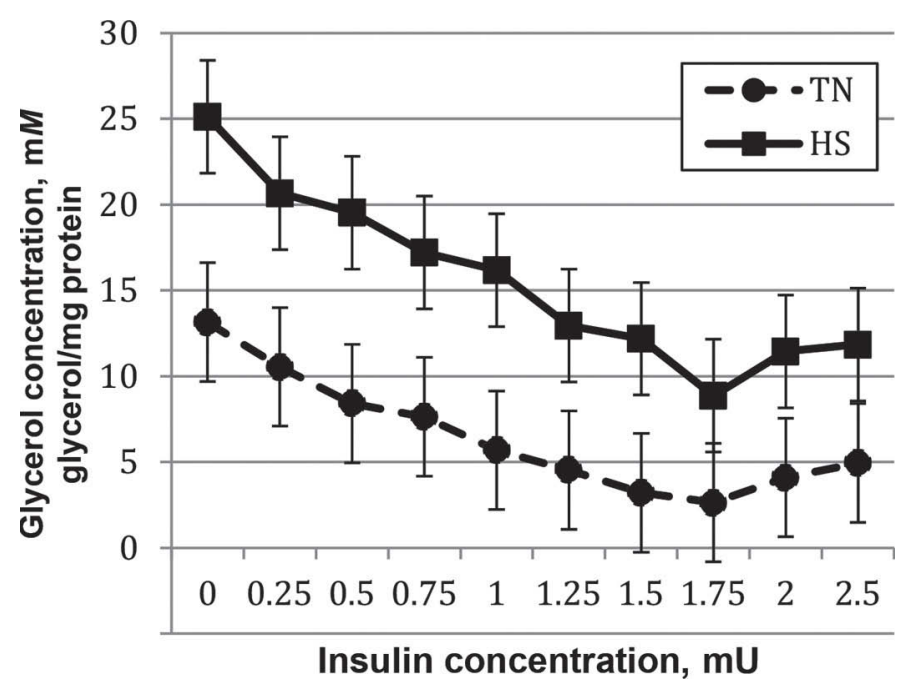

Figure 2. Effect of heat stress (HS) on inhibition of stimulated lipolysis by insulin. Medium glycerol concentration was measured as an indicator of the lipolytic response of bovine primary adipocytes to isoproterenol in the presence of insulin. Data represent the average glycerol concentration across cells isolated from 5 cows for each insulin by temperature (HS or thermal neutral, $\mathrm{TN}$ ) treatment combination, and SE bars. 
at lower concentrations of ISO. However, chi-squared test results showed that phosphorylated perilipin was detected more often $(P=0.02)$ with higher concentrations of ISO as compared with control (no ISO) in both HS and TN cells. Comparison of phosphorylated perilipin at these higher ISO concentrations indicated a significant effect of thermal treatment $(P=0.03)$, with greater abundance of phosphorylated perilipin in HS compared with TN cells (Figure 4C). Heat stress did not affect adipose triglyceride lipase (ATGL) abundance in isolated bovine adipocytes (Figure 4A). Likewise, ATGL abundance did not change significantly across different ISO concentrations.

\section{TN}
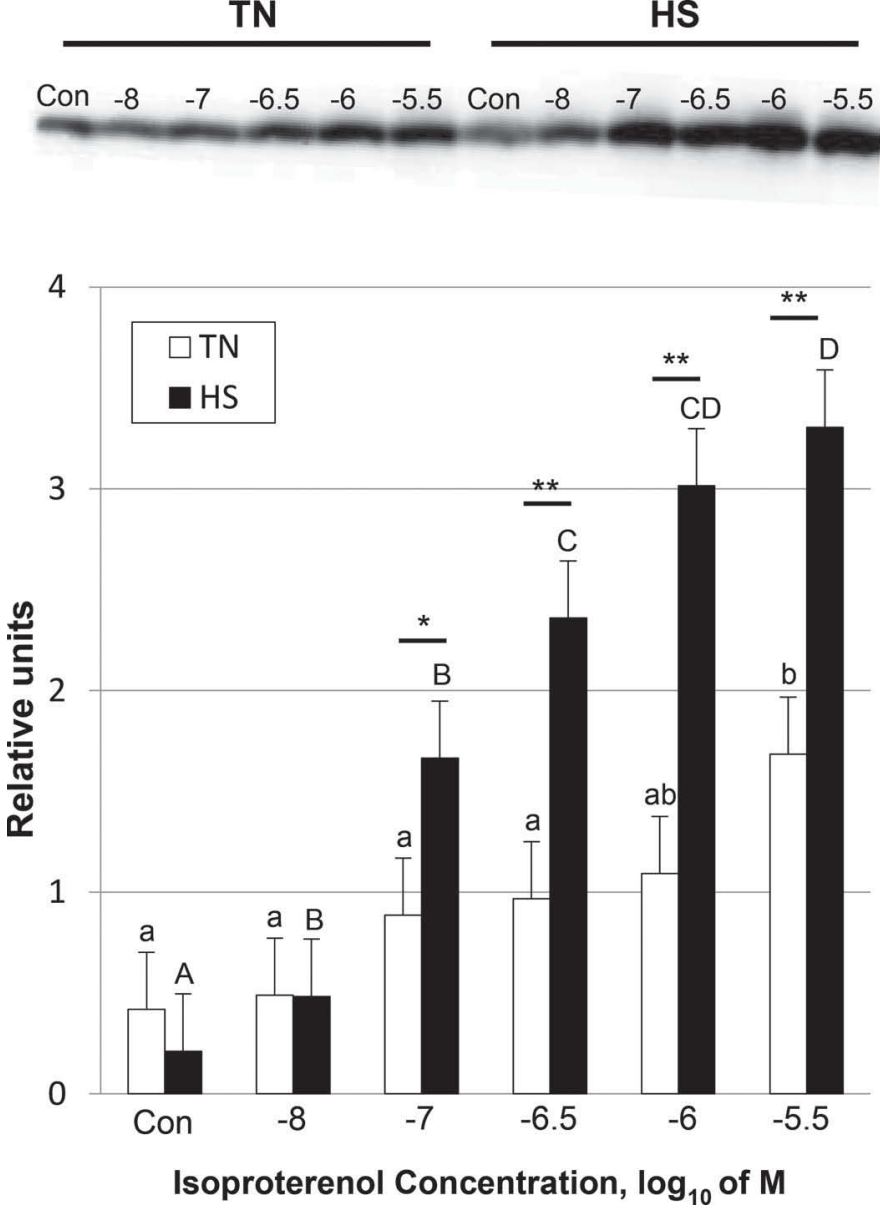

Figure 3. Protein abundance and SE of hormone-sensitive lipase (HSL) phosphorylated at serine residue 563. Phosphorylation of HSL at serine 563 was evaluated upon treatment of bovine primary adipocytes with varying concentrations of isoproterenol (ISO) and after incubation at either $42^{\circ} \mathrm{C}$ (heat stress, HS) or $37^{\circ} \mathrm{C}$ (thermal neutral, TN). Protein abundance was determined via semiquantitative Western blotting, expressed as relative units and normalized to a common standard. The inset shows a representative Western blot. Lowercase letters correspond to differences across ISO concentrations under TN conditions; uppercase letters indicate differences across ISO concentrations under HS. Bars indicate significant differences between temperature treatments $\left({ }^{*} P \leq 0.05,{ }^{* *} P \leq 0.001\right)$. Con $=$ control.
A

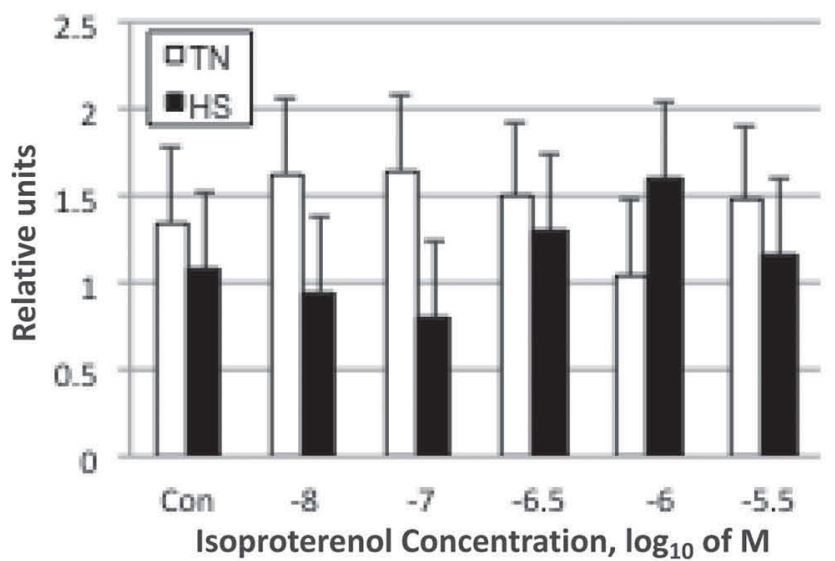

B

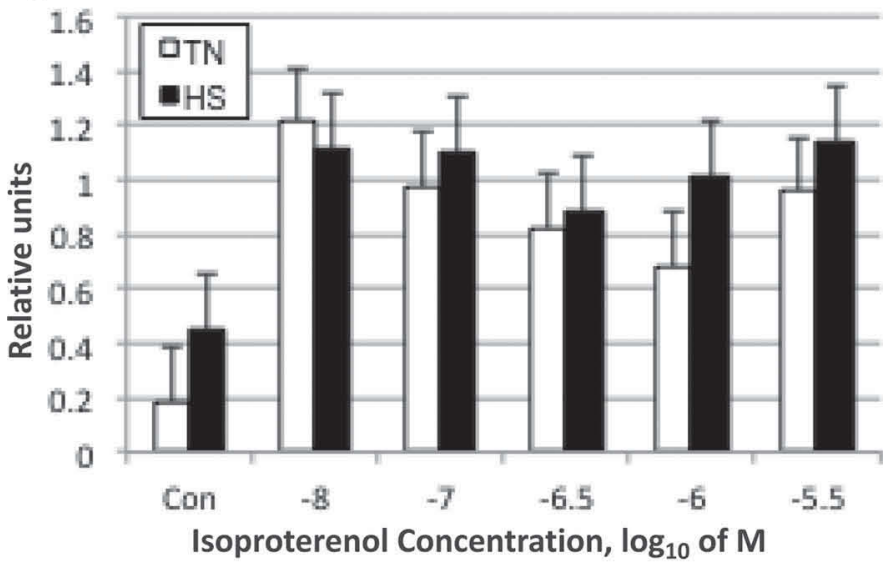

C

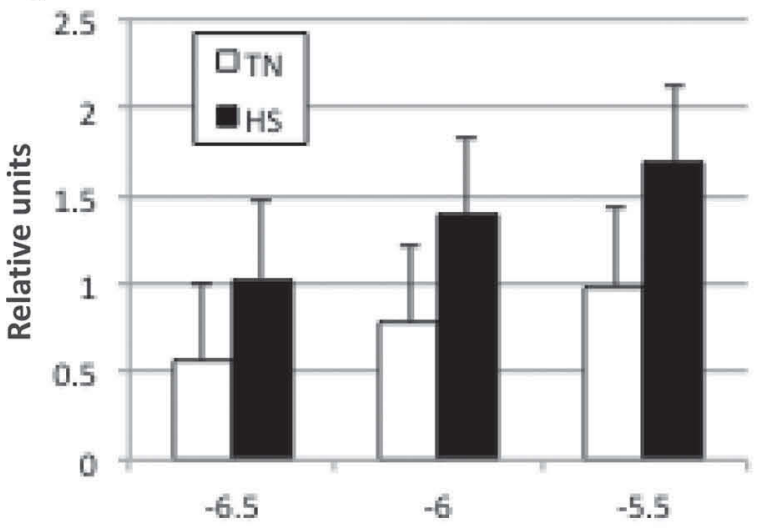

Isoproterenol Concentration, $\log _{10}$ of $\mathrm{M}$

Figure 4. Protein abundance of (A) adipose triglyceride lipase (ATGL), (B) perilipin, and (C) phosphorylated perilipin. Protein samples used for semiquantitative Western blotting were extracted from bovine primary adipocytes treated with varying concentrations of isoproterenol and incubated at either $42^{\circ} \mathrm{C}$ (heat stress, HS) or $37^{\circ} \mathrm{C}$ (thermal neutral, TN). Amount and SE of protein is expressed as relative units after normalization with a common standard. Thermal treatment altered the abundance of phosphorylated perilipin $(P=$ 0.03 ) but not total perilipin or ATGL. Con $=$ control. 


\section{Effects of HS on Lipogenesis}

The effect of HS on lipogenic activity was evaluated by determining the amount of acetate incorporated into lipids of bovine primary adipocytes. The overall effect of insulin was significant, with increased acetate incorporation occurring with increasing insulin concentration $(P<0.001$; Figure 5A). Effects of temperature treatment and the interaction between temperature and insulin were not significant $(P=0.32$ and $P=$ 0.25 , respectively). A temperature by insulin interaction was observed for the abundance of phosphorylated acetyl CoA carboxylase (ACC; $P=0.01$; Figure 5B). A decrease in phosphorylated ACC abundance with insulin was observed for cells cultured at TN $(P=0.02)$ but not HS $(P>0.05)$.

\section{DISCUSSION}

An in-depth analysis of the economic effects of HS (St-Pierre et al., 2003) indicated that in the United States alone, billions of dollars of lost productivity and impaired animal health in the dairy industry are attributed to HS. A prerequisite to developing mitigation strategies to minimize HS-associated metabolic abnormalities is a better understanding of how environmentally induced hyperthermia affects postabsorptive metabolism and energy partitioning. Heat-stressed mammals undergo changes in thermoregulatory mechanisms designed to promote body heat loss, which ultimately affect metabolic and hormonal responses as well as alter substrate utilization. In vivo data indicate that lactating cattle experiencing HS have a diminished lipolytic response to changes in energy status (Rhoads et al., 2009; Schwartz et al., 2009) and have reduced responsiveness to norepinephrine (Baumgard and Rhoads, 2013). Thus, we hypothesized that HS directly affects adipose tissue by altering its response to lipolytic and lipogenic signals.

For the present study, we used isolated primary adipocytes from lactating dairy cattle to evaluate the direct effects of HS on lipolysis stimulated by ISO. When interpreting results of the experiments described herein, it is important to note several points. First, the HS treatment applied in these studies may be quite physiologically different from the stress experienced in vivo. In the current experiments, the temperature chosen for the HS treatment is quite high. This temperature was chosen because it reflects an extreme HS event and has been used previously to represent acute thermal stress in cultured bovine cells (Collier et al., 2006). Additionally, published research using mouse and rat adipocytes also employed HS treatments that were 3 to $4^{\circ} \mathrm{C}$ above body temperature (Jiang et al., 2007; Bernabucci et al.,
2009). Second, adipocytes in the current experiments experienced acute HS, whereas the HS described by in vivo experiments is likely to be more gradual and chronic. Although the current experiments provide insight to the acute reaction of adipocytes to extreme HS, it is currently unknown how cells may adapt to HS over time. Third, the results described may be dependent on the adipose tissue sampled. The subcutaneous adipose tissue was biopsied in the current experiment because of its accessibility. However, it is unknown if cells from other depots would respond similarly to the HS treatment. Significant differences among depots have been
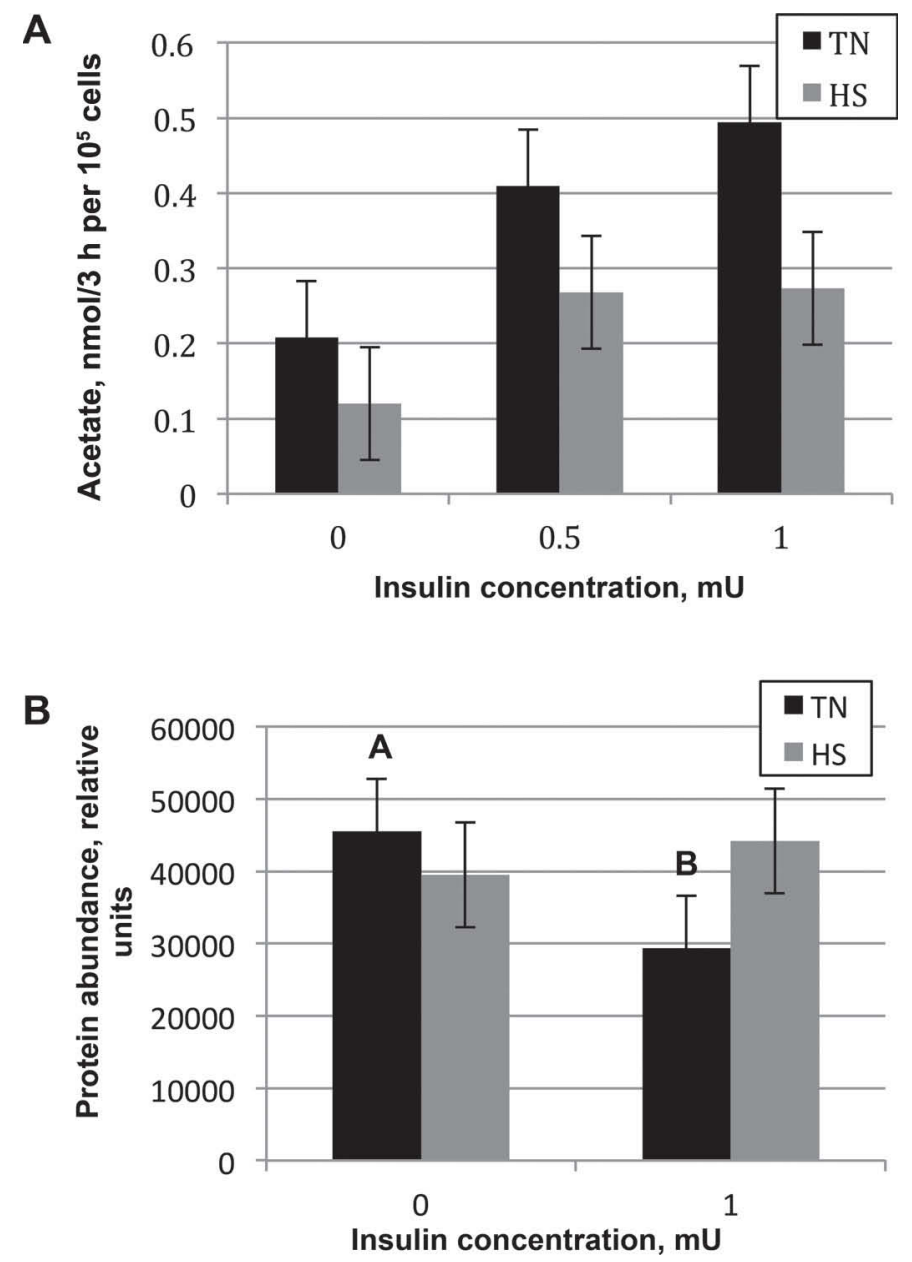

Figure 5. Effect of heat stress (HS) on the lipogenic response to insulin. (A) Lipogenesis was monitored as the incorporation of radiolabeled acetate into total lipid. The main effect of insulin was significant $(P<0.001)$, but main effects of temperature and temperature by insulin interaction were not $(P>0.05)$. (B) Activation of acetyl CoA carboxylase (ACC) was monitored by semiquantitative Western blot analysis of phosphorylated ACC. A significant temperature by insulin interaction was observed $(P=0.01)$. Within temperature treatment, means with different letters $($ A.B $)$ differ $(P<0.05)$. Data are means and SE from bovine primary adipocytes isolated from 8 cows and cultured under HS $\left(42^{\circ} \mathrm{C}\right)$ or thermal neutral $\left(\mathrm{TN}, 37^{\circ} \mathrm{C}\right)$ conditions in the presence or absence of insulin. 
documented in other experiments involving lactating dairy cows (Locher et al., 2011; Ji et al., 2014; Kenez et al., 2015), and such differences may be reflected by in vivo experiments. Finally, the current experiment used late lactation cows with excess body condition, whereas in vivo experiments used cows in earlier stages of lactation. Differences in adipose tissue across stage of lactation have been described (Koltes and Spurlock, 2011; Kenez et al., 2015), and it is unknown if adipocytes from leaner cows or cows in a different stage of lactation would respond similarly to those used in the current experiments. Nevertheless, the current experiments provide novel and important data documenting the direct response of bovine adipocytes to an acute and severe HS treatment. Future experiments are now warranted to refine our understanding of these events in additional adipose depots representing cows from additional stages of lactation and acclimation to HS.

Our findings indicate that exposure of isolated adipocytes to HS significantly increased their maximal response and sensitivity to ISO. This result was unexpected, as previous studies in vivo have reported that heat-stressed dairy cattle are refractory to lipolytic signals (Rhoads et al., 2009; Schwartz et al., 2009; Baumgard and Rhoads, 2013). We performed preliminary experiments using the PrestoBlue Cell Viability Reagent (Life Technologies; data not shown) to confirm cell viability was not affected by our HS protocol, suggesting that the temperature-related differences observed in the lipolytic response to ISO were the result of a direct effect of HS on the metabolic activity of adipocytes.

It is important to note that the maximal lipolytic response diminished at the highest dose of ISO evaluated in cells cultured under HS, but not TN conditions. Isoproterenol initiates a lipolytic response by activation of BAR. The BAR undergo decreased sensitivity to agonists following prolonged exposure (Benovic et al., 1988) and this downregulation of BAR is particularly apparent in adipose tissue (Spurlock et al., 1994). Previous studies have reported that acute HS causes a marked increase in circulating cortisol, norepinephrine, and epinephrine levels (Bernabucci et al., 2010; Farooq et al., 2010), catabolic signals that normally stimulate lipolysis via BAR activation. Thus, it is possible that adipocytes initially experience increased sensitivity to BAR agonists during HS in vivo, and this increased sensitivity contributes to desensitization of the receptor. Continued exposure to HS may lead to the downregulation of BAR, such that a diminished response to BAR agonists is then observed in vivo. Alternatively, the decline in lipolytic response with high concentration of ISO may be associated with the activation of adenosine receptors. Evidence of adenosine accumulation in response to metabolic stress has been observed
(Fredholm et al., 2001; Linden, 2001), and activation of adenosine $A_{1}$ receptor $\left(\mathbf{A}_{1} \mathbf{R}\right)$ has been linked to $G_{i^{-}}$ mediated inhibition of adenylyl cyclase (Hasko et al., 2008). Therefore, the elevated levels of epinephrine and insulin observed in vivo during HS may contribute to a decline in the lipolytic response by activating $\mathrm{A}_{1} \mathrm{R}$ and negating BAR response.

To further investigate the mechanisms by which HS affects the response of adipocytes to lipolytic signals, the abundance and phosphorylation of several proteins involved in the regulation of lipolysis were evaluated. The role of HSL in the lipolytic pathway is well documented, and its activity is regulated by phosphorylation and translocation to the lipid droplet (Yin et al., 2003; Koltes and Spurlock, 2011; van der Drift et al., 2013). In particular, HSL is activated when phosphorylated at serine residue 563 by protein kinase A (PKA; Ronchi et al., 1999; Roepstorff et al., 2004) although several other phosphorylation sites may also be involved (Anthonsen et al., 1998; Holm et al., 2000). Together with ATGL, HSL is responsible for about $95 \%$ of the triglyceride hydrolase activity in murine white adipose tissue (Schweiger et al., 2006). Our results demonstrating increased phosphorylation of $\mathrm{HSL}_{\mathrm{Ser} 563}$ in cells cultured under HS conditions are consistent with increased sensitivity of BAR and activation of the PKA pathway with HS. The protein abundance of total HSL and ATGL did not differ with thermal stress, providing further evidence that the observed lipolytic changes were due to posttranslational signals. These results are consistent with those described for rat adipocytes in response to endoplasmic reticulum stress, in that endoplasmic reticulum stress contributed to increased PKA activation, resulting in increased phosphorylation of HSL at Ser 563 and moderately elevated translocation of HSL from the cytosol to lipid droplets, without significant changes in HSL and ATGL protein abundance (Deng et al., 2012). Similarly, phosphorylation of perilipin increased with HS. The function of perilipin as a lipolytic regulator via phosphorylation from the PKA pathway is firmly established. (Egan et al., 1990; Greenberg et al., 1991).

Increased insulin sensitivity has been described for animals experiencing HS in vivo (Baumgard and Rhoads, 2013). Therefore, we investigated the interaction between thermal treatment and insulin administration to investigate their lipolytic and lipogenic effects on adipocytes cultured under HS conditions. Insulin inhibition of lipolysis in the presence of ISO was similar for TN and HS treated cells, suggesting that the lipolytic inhibitory effect of insulin is not altered by the direct effects of HS under the conditions studied. However, the intact antilipolytic response to insulin, combined with increased levels of circulating insulin in vivo, may represent a coping mechanism by 
which heat stressed animals counteract high lipolytic stimulation or decrease (or both) of metabolic heat production (Baumgard and Rhoads, 2013). The direct effect of HS on lipogenesis in bovine adipocytes was also investigated in this study. Although the expected effect of insulin on lipogenesis was observed, lipogenesis measured as the rate of acetate incorporation in lipids was not altered by thermal treatment. However, Western blot analysis of ACC revealed that phosphorylation of ACC decreased in cells cultured at TN but not HS temperatures. This enzyme catalyzes the first step in FA synthesis, and phosphorylation events render ACC to be less active. Thus, the significant treatment interaction for phosphorylated ACC could indicate that cells exposed to HS are less responsive to the lipogenic signals of insulin, as compared with adipocytes cultured in $\mathrm{TN}$ conditions.

In conclusion, hyperthermia has the potential to directly influence adipose metabolism. Results of our study suggest that acute HS directly increases the response of bovine primary adipocytes to lipolytic signals, and that this response is mediated in part through increased PKA phosphorylation of HSL and perilipin. However, increased sensitivity to BAR agonists may also contribute to increased downregulation of BAR or activation of $A_{1} R$ during HS, potentially contributing to the diminished lipolytic response that has been described during HS in vivo. Furthermore, the antilipolytic effect of insulin was not significantly altered by the direct effect of HS on cultured adipocytes, suggesting the increased circulating insulin concentrations observed in vivo may contribute to the blunted lipolytic response that is also observed. Finally, insulin stimulated lipogenesis in cultured adipocytes, but acute HS diminished insulin-stimulated activation of the ratelimiting enzyme ACC.

\section{ACKNOWLEDGMENTS}

This project was supported by National Research Initiative Competitive Grant no. 2010-65206-20206 from the USDA National Institute of Food and Agriculture.

\section{REFERENCES}

Anthonsen, M. W., L. Rönnstrand, C. Wernstedt, E. Degerman, and C. Holm. 1998. Identification of novel phosphorylation sites in hormone-sensitive lipase that are phosphorylated in response to isoproterenol and govern activation properties in vitro. J. Biol. Chem. 273:215-221.

Baumgard, L. H., and R. P. Rhoads. 2013. Effects of heat stress on postabsorptive metabolism and energetics. Annu. Rev. Anim. Biosci. 1:311-337. http://dx.doi.org/10.1146/annurevanimal-031412-103644.
Benovic, J., M. Bouvier, M. Caron, and R. Lefkowitz. 1988. Regulation of adenyl cyclase-coupled $\beta$-adrenergic receptors. Annu. Rev. Cell Biol. 4:405-428.

Bernabucci, U., L. Basirico, P. Morera, N. Lacetera, B. Ronchi, and A. Nardone. 2009. Heat shock modulates adipokines expression in 3T3-L1 adipocytes. J. Mol. Endocrinol. 42:139-147.

Bernabucci, U., N. Lacetera, L. Basirico, B. Ronchi, P. Morera, E. Seren, and A. Nardone. 2006. Hot season and BCS affect leptin secretion in periparturient dairy cows. J. Dairy Sci. 89:348.

Bernabucci, U., N. Lacetera, L. H. Baumgard, R. P. Rhoads, B. Ronchi, and A. Nardone. 2010. Metabolic and hormonal acclimation to heat stress in domesticated ruminants. Animal 4:1167-1183. http://dx.doi.org/10.1017/S175173111000090X.

Bernabucci, U., N. Lacetera, B. Ronchi, and A. Nardone. 2002. Markers of oxidative status in plasma and erythrocytes of transition dairy cows during hot season. J. Dairy Sci. 85:2173-2179.

Collier, R. J., C. M. Stiening, B. C. Pollard, M. J. VanBaale, L. H. Baumgard, P. C. Gentry, and P. M. Coussens. 2006. Use of gene expression microarrays for evaluating environmental stress tolerance at the cellular level in cattle. J. Anim. Sci. 84:E1-E13.

Deng, J., S. Liu, L. Zou, C. Xu, B. Geng, and G. Xu. 2012. Lipolysis response to endoplasmic reticulum stress in adipose cells. J. Biol. Chem. 287:6240-6249. http://dx.doi.org/10.1074/jbc. M111.299115.

Egan, J. J., A. S. Greenberg, M. K. Chang, and C. Londos. 1990. Control of endogenous phosphorylation of the major cAMP-dependent protein kinase substrate in adipocytes by insulin and beta-adrenergic stimulation. J. Biol. Chem. 265:18769-18775.

Elkins, D. A., and D. M. Spurlock. 2009. Phosphorylation of perilipin is associated with indicators of lipolysis in Holstein cows. Horm. Metab. Res. 41:736-740. http://dx.doi.org/10.1055/s-0029-1225359.

Farooq, U., H. A. Samad, F. Shehzad, and A. Qayyum. 2010. Physiological responses of cattle to heat stress. World Appl. Sci. J. 8:38-43.

Faylon, M. P., D. E. Koltes, and D. M. Spurlock. 2014. Regulation of lipid droplet-associated proteins following growth hormone administration and feed restriction in lactating Holstein cows. J. Dairy Sci. 97:2847-2855. http://dx.doi.org/10.3168/jds.2013-7565.

Fredholm, B. B., F. Irenius, B. Kull, and G. Schulte. 2001. Comparison of the potency of adenosine as an agonist at human adenosine receptors expressed in Chinese hamster ovary cells. Biochem. Pharmacol. 61:443-448.

Greenberg, A. S., J. J. Egan, S. A. Wek, N. B. Garty, E. J. BlanchetteMackie, and C. Londos. 1991. Perilipin, a major hormonally regulated adipocyte-specific phosphoprotein associated with the periphery of lipid storage droplets. J. Biol. Chem. 266:11341-11346.

Hasko, G., J. Linden, B. Cronstein, and P. Pacher. 2008. Adenosine receptors: Therapeutic aspects for inflammatory and immune disease. Nat. Rev. Drug Discov. 7:759-770. http://dx.doi. org $/ 10.1038 / \operatorname{nrd} 2638$.

Holm, C., T. Østerlund, H. Laurell, and J. A. Contreras. 2000. Molecular mechanisms regulating hormone sensitive lipase and lipolysis. Annu. Rev. Nutr. 20:365-393.

Ji, P., J. K. Drakely, M. J. Kahn, and J. J. Loor. 2014. Inflammation and lipid metabolism related gene network expression in visceral and subcutaneous adipose depots of Holstein cows. J. Dairy Sci. 97:3441-3448. http://dx.doi.org/10.3168/jds.2013-7296.

Jiang, H., J. He, S. Pu, C. Tang, and G. Xu. 2007. Heat shock protein 70 is translocated to lipid droplets in rat adipocytes upon heat stimulation. Biochim. Biophys. Acta 1771:66-74.

Kenez, A., A. Kulcsar, F. Kluge, I. Benebelkacem, K. Hansen, L. Locher, J. Rehage, S. Danicke, and K. Huber. 2015. Changes of adipose tissue morphology and composition during late pregnancy and early lactation in dairy cows. PLoS ONE 10:e0127208. http:// dx.doi.org/10.1371/journal.pone.0127208.

Kershaw, E. E., and J. S. Flier. 2004. Adipose tissue as an endocrine organ. J. Clin. Endocrinol. Metab. 89:2548-2556. http://dx.doi. org/10.1210/jc.2004-0395.

Koltes, D. A., and D. M. Spurlock. 2011. Coordination of lipid dropletassociated proteins during the transition period of Holstein dairy 
cows. J. Dairy Sci. 94:1839-1848. http://dx.doi.org/10.3168/ jds.2010-3769.

Linden, J. 2001. Molecular approach to adenosine receptors: receptormediated mechanisms of tissue protection. Annu. Rev. Pharmacol. Toxicol. 41:775-787.

Locher, L. F., N. Meyer, E. M. Weber, J. Rehage, U. Meyer, S. Danicke, and K. Huber. 2011. Hormone sensitive lipase protein expression and extent of phosphorylation nin subcutaneous and retroperitoneal adipose tissues in the periparturient dairy cow. J. Dairy Sci. 94:4514-4523. http://dx.doi.org/10.3168/jds.2011-4145.

O'Brien, M. D., R. P. Rhoads, S. R. Sanders, G. C. Duff, and L. H. Baumgard. 2010. Metabolic adaptations to heat stress in growing cattle. Domest. Anim. Endocrinol. 38:86-94. http://dx.doi. org/10.1016/j.domaniend.2009.08.005.

Rhoads, M. L., R. P. Rhoads, M. J. VanBaale, R. J. Collier, S. R. Sanders, W. J. Weber, B. A. Crooker, and L. H. Baumgard. 2009. Effects of heat stress and plane of nutrition on lactating Holstein cows: I. Production, metabolism, and aspects of circulating somatotropin. J. Dairy Sci. 92:1986-1997. http://dx.doi. org/10.3168/jds.2008-1641.

Roepstorff, C., B. Vistisen, M. Donsmark, J. N. Nielsen, H. Galbo, K. A. Green, D. G. Hardie, J. F. P. Wojtaszewski, E. A. Richter, and B. Kiens. 2004. Regulation of hormone-sensitive lipase activity and Ser563 and Ser565 phosphorylation in human skeletal muscle during exercise. J. Physiol. 560:551-562. http://dx.doi.org/10.1113/ jphysiol.2004.066480.

Ronchi, B., U. Bernabucci, N. Lacetera, A. Verini Supplizi, and A. Nardone. 1999. Distinct and common effects of heat stress and restricted feeding on metabolic status in Holstein heifers. Zoot. Nutr. Anim 25:71-80.

Ronchi, B., G. Stradaioli, A. Verini Supplizi, U. Bernabucci, N Lacetera, P. A. Accorsi, A. Nardone, and E. Seren. 2001. Influence of heat stress and feed restriction on plasma progesterone, estradiol-17b, LH, FSH, prolactin and cortisol in Holstein heifers. Livest. Prod. Sci. 68:231-241.
SAS Institute Inc. 1999. SAS/STAT User's Guide. SAS Institute Inc. Cary, NC.

Schweiger, M., R. Schreiber, G. Haemmerle, A. Lass, C. Fledelius, P. Jacobsen, H. Tornqvist, R. Zechner, and R. Zimmermann. 2006. Adipose triglyceride lipase and hormone-sensitive lipase are the major enzymes in adipose tissue triacylglycerol catabolism. J. Biol. Chem. 281:40236-40241. http://dx.doi.org/10.1074/jbc. M608048200.

Shwartz, G., M. L. Rhoads, M. J. VanBaale, R. P. Rhoads, and L. H. Baumgard. 2009. Effects of a supplemental yeast culture on heatstressed lactating Holstein cows. J. Dairy Sci. 92:935-942. http:// dx.doi.org/10.3168/jds.2008-1496.

Spurlock, M., J. Cusumano, S. Ji, D. Anderson, C. Smith II, D. Hancock, and S. Mills. 1994. The effect of ractopamine on beta-adrenoreceptor density and affinity in porcine adipose and skeletal muscle tissue. J. Anim. Sci. 72:75-80.

St-Pierre, N. R., B. Cobanov, and G. Schnitkey. 2003. Economic losses from heat stress by US livestock industries. J. Dairy Sci. 86:E52E77.

van der Drift, S. G., R. R. Everts, M. Houweling, L. A. van Leengoed, J. A. Stegeman, A. G. Tielens, and R. Jorritsma. 2013. Effects of $\beta$-hydroxybutyrate and isoproterenol on lipolysis in isolated adipocytes from periparturient dairy cows and cows with clinical ketosis. Res. Vet. Sci. 94:433-439. http://dx.doi.org/10.1016/j. rvsc.2012.11.009.

Wheelock, J. B., R. P. Rhoads, M. J. Vanbaale, S. R. Sanders, and L. H. Baumgard. 2010. Effects of heat stress on energetic metabolism in lactating Holstein cows. J. Dairy Sci. 93:644-655. http://dx.doi. org/10.3168/jds.2009-2295.

Yin, W., J. Mu, and M. J. Birnbaum. 2003. Role of AMP-activated protein kinase in cyclic AMP-dependent lipolysis In 3T3-L1 adipocytes. J. Biol. Chem. 278:43074-43080. http://dx.doi.org/10.1074/ jbc.M308484200. 